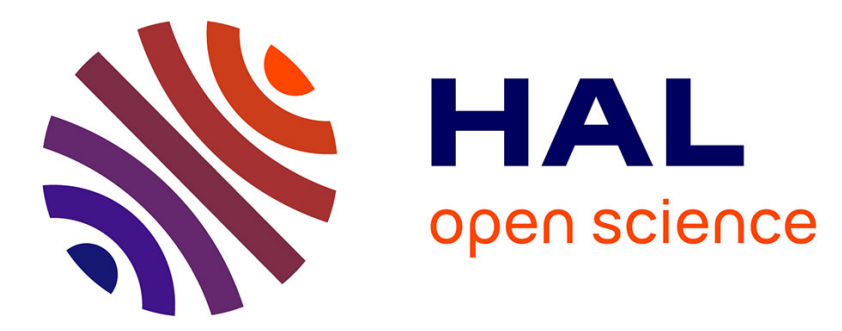

\title{
Electrochemical exfoliation in real time of natural graphite deposited onto glassy carbon. Doping and modifying carbons through ultra-thin graphite layers
}

\author{
Jacques Simonet
}

\section{To cite this version:}

Jacques Simonet. Electrochemical exfoliation in real time of natural graphite deposited onto glassy carbon. Doping and modifying carbons through ultra-thin graphite layers. Electrochemistry Communications, 2014, 48, pp.142 - 146. 10.1016/j.elecom.2014.08.031 . hal-01072588

\author{
HAL Id: hal-01072588 \\ https://hal.science/hal-01072588
}

Submitted on 8 Oct 2014

HAL is a multi-disciplinary open access archive for the deposit and dissemination of scientific research documents, whether they are published or not. The documents may come from teaching and research institutions in France or abroad, or from public or private research centers.
L'archive ouverte pluridisciplinaire HAL, est destinée au dépôt et à la diffusion de documents scientifiques de niveau recherche, publiés ou non, émanant des établissements d'enseignement et de recherche français ou étrangers, des laboratoires publics ou privés. 


\title{
Electrochemical exfoliation in real time of \\ natural graphite deposited onto glassy carbon.
}

Doping and modifying carbons through ultra-thin graphite layers.

\author{
Jacques Simonet* \\ *) Laboratoire MaSCE, UMR 6226, Université de Rennes 1, Campus de Beaulieu, 35042 \\ Rennes Cedex, France.
}

\begin{abstract}
Natural graphite, deposited onto smooth glassy carbon, when reduced (around -2V vs. $\mathrm{Ag} / \mathrm{AgCl}$ ) in the presence of tetraalkylammonium salts (TAAX) in aprotic polar solvents, lead to spectacular exfoliation processes followed in real time in the course of voltammetric scans. The method permits to get extraordinary stable modified carbon surfaces, with quite simple voltammetric responses ( 1 to 4 reversible cathodic steps) that strongly depend on the nature of the cations used. Those cathodic steps exhibit currents quasi perfectly proportional to the scan rate. It is expected the formation of a graphene-like substrate. Surface modifications both by ferrocene and anthraquinone could underline the originality of those new materials
\end{abstract}

Key Words: Graphite; Exfoliation; Graphene surfaces; Modified carbon electrodes.

\section{Introduction}

Glassy carbon (GC) is considered as a convenient electrode material for achieving analysis and macro-electrolyses, especially within the cathodic domain [1]. A large panel of electro-organic reactions were carried out within a quite extended cathodic domain at negatively polarized carbon and this material remains very useful to conduct electrochemical reactions at potentials $<-2 \mathrm{~V}$ in dry polar organic solvents. Morever, it has been reported that $\mathrm{GC}$ at $\mathrm{E}<-1.7 \mathrm{~V}$, is not longer totally inert owing the presence of ribbons of graphite-like structures [2-3]. Cathodic charging (by insertion of organic or inorganic cations) of these 
different "impurities" has been used for inducing specific reactions with a large palette of electrophilic reagents [4].

Independently, it is worth recalling that, when polar organic solvents are used, cathodic charge of highly oriented pyrolytic graphite [5] specifically leads to well defined insertion stages $\left[\mathrm{C}_{\mathrm{n}}^{-}, \mathrm{TAA}^{+}\right]$via concomitant insertion of electrons and tetraalkylammonium salts (TAAX). Fixed potential reduction and exfoliation of natural graphite by bulky ammonium salts has been reported [6]. The electrochemical synthesis of those "graphite salts", rather similar to $\{$ TAA-amalgams $\}$, has to be considered both as a novel generation of reducing species and as poly-nucleophilic materials (then reactive with organic reagents for modification of graphites and carbons [7]).

Under these conditions, graphite appears to be a key substrate to create via several methods graphene plans. In electrochemistry, the basic method remains the reduction of graphene oxide [8]. The catholic reduction of commercial graphene has been achieved and 3D \{graphene-GC\} electrodes described. Recently, electrochemical functionalizations of graphene were reported [9].

The early method [6] for a facile exfoliation of graphite by means of electrochemistry (reduction at about $-2.0 \mathrm{~V}$ ) remains certainly a fascinating manner to generate in situ at electrified solid substrates thin graphene layers. We here describe a new process for achieving natural graphite exfoliation concomitantly with deposition onto glassy carbon.

\section{Experimental section}

Voltammetries were carried out in $0.1 \mathrm{M}$ solutions of tetraalkylammonium salts (TAAX) such as tetramethylammonium $\left(\mathrm{TMABF}_{4}\right)$, tetraethylammonium $\left(\mathrm{TEABF}_{4}\right)$, tetra- $n$ butylammonium $\left(\mathrm{TBABF}_{4}\right)$, and tetra- $n$-octylammonium tetrafluoroborate $\left(\mathrm{TOABF}_{4}\right)$, and dissolved in upper grade dimethylformamide (DMF). Experiments described in this work did not need special treatment of electrolytic solutions. 
Potentials are referred to the aqueous $\mathrm{Ag} / \mathrm{AgCl} / \mathrm{KCl}_{\text {(sat) }}$. Voltammetric and coulometric measurements were performed using three-electrode cells separated with a fritted glass. The electrochemical instrumentation has been previously reported [7].

GC rods electrodes as substrates used for graphite deposition had geometric area of 1 and $7 \mathrm{~mm}^{2}$. All those carbon samples were purchased from Tokai Carbon $\mathrm{C}^{\circ}$ (code: GC Rod) and Carbone Lorraine carbon vitreous VD 1500. Also, large GC plates (from Carbone Lorraine) were also employed for building flat electrodes of much larger area.

Prior to being modified by deposition of natural graphite, GC substrates were carefully polished first with silicon carbide paper (Struers 500) and then with a thinner polishing paper (Struers 1200). Then, natural graphite (from Ceylon) or highly oriented pyrolytic graphite (HOPG), both first partly exfoliated by the electrolytic method already quoted [6] were disposed on a carbon planar surface. Deposition of graphite was done using glassy cardboard and the surface was rubbed by firmly polishing electrodes until obtaining a shiny aspect of carbon. The final process for deposit final exfoliation is fully described below in $\S 3.1$.

\section{Experimental results and procedures}

\subsection{Evidences for real time exfoliation procedures with natural graphite}

First of all, an exfoliated graphite coating (electrolysis in DMF accordingly to reference [6] i.e. at mercury pool, potential $-2.1 \mathrm{~V}$, amount of electricity: $12 \mathrm{C} / 1 \mathrm{~g}$ of Ceylon graphite) was achieved at a $\mathrm{GC}$ disk and electrolyzed in $\mathrm{DMF} / \mathrm{TMAClO}_{4}$. A typical voltammetry is displayed in Figure $1 \mathrm{~A}$ : while the GC disk polished according to the procedure given in the experimental does not display any strong signal, an intense signal assigned to the exfoliation process is obtained from the first scan. From $-1.7 \mathrm{~V}$, i.e. a potential reported to correspond to the cathodic charge threshold of graphite, the huge increase of current is immediately followed $(\approx-2 \mathrm{~V})$ by a sudden decay. The anodic discharge, still rather intense is observed. Furthers scans (scans 2 and 3) show a progressive crushing of charge/discharge processes until very reproducible signals (in potential and intensity) apparently specific of used $\mathrm{TAA}^{+}$ salts. In general, with scans up to $-2.3 \mathrm{~V}$, peaks (their number $\leq 4$ essentially depending on the 
employed $\mathrm{TAA}^{+}$electrolyte) are obtained. They are assigned to the electrochemical reduction (or charge) of a few remaining layers of graphite immobilized at the GC interface presumably by mean of $\pi, \pi$-interactions with the substrate. Exfoliation with $\mathrm{TMA}^{+}$is considered as a formatting process and allows testing behaviors of several ammonium salts that all exhibit specific responses. Some of them are displayed in Figure $1 \mathrm{~B}$.

Reduction of graphite deposits onto GC (before exfoliation) revealed different points: in the course of the first sweep, some small reduction peaks are observed around $-1 \mathrm{~V}$ and are assigned to electroactive edge impurities provoked by the aging of graphite in contact with air (such as ketonyl and quinonyl groups, aromatic carboxylic acids). After three scans, reversible electrochemical steps are observed at $\mathrm{E}<-1.8 \mathrm{~V}$ and assigned to stable graphitic (or graphene) layer(s). Thus, in the specific case of tetraethylammonium of salts (triflate, tetrafluoroborate or perchlorate) in DMF, three well defined reversible steps are obtained (see curve $\mathrm{C}$ in Figure 1). Their peak currents are strictly proportional to the scan rate (until $1 \mathrm{~V} \mathrm{~s}^{-1}$ ) and could be assigned to the reduction of graphene mono-layers although re-arrangement of those layers into "graphite-like" by means of $\pi, \pi$-interactions can reasonably envisaged. This kind of interaction could also contribute to fix graphene layers onto GC. Moreover, cathodic responses of those GC modified surfaces are particularly stable upon charge/discharge cyclings.

In $\mathrm{TMAClO}_{4} / \mathrm{DMF}$, half-peak potentials of four reduction steps are with $\mathrm{I}\left(\mathrm{E}_{\mathrm{I}}=-1.76 \mathrm{~V}\right)$, II $\left(E_{I I}=-1.97 \mathrm{~V}\right)$, III $\left(E_{I I I}=-2.10 \mathrm{~V}\right)$ and IV $\left(E_{I V}=-2.22 \mathrm{~V}\right)$. Those values are quite close and definitively do not correspond to charge potentials of graphite already reported with HOPG under very comparable conditions (chronopotentiometric curves with total filling of layers by $\left.\mathrm{TMA}^{+}[4]\right)$. Also, voltammetries of commercial graphene in the same electrolyte verified that similar responses were obtained, however without comparable results in terms of stability and intensity. Lastly, analytical determination of synthesized graphenes [10] at carbon electrodes led to comparable successive reversible cathodic peaks.

\subsection{Deposition of graphite via exfoliation processes in the contact of other $T_{A A^{+}}$salts}


Once the deposition of graphite in very thin layers (Scheme 1, A) was first formatted with $\mathrm{TMA}^{+}$, cycling's of those GC/graphite interfaces were undertaken with different $\mathrm{TAA}^{+}$ salts in DMF. When radii of cations increase, global charge intensities (observed between $1.7 \mathrm{~V}$ and $-2.3 \mathrm{~V}$ with a given scan rate) decay and noticed cathodic charge steps were progressively shifted to more negative potentials. From $\mathrm{TMA}^{+}$to $\mathrm{TBA}^{+}$, maximum charge (area of $7 \mathrm{~mm}^{2}$ ) values decline from $25 \times 10^{-4} \mathrm{C}$ to $3.9 \times 10^{-4} \mathrm{C}$. Very bulky salts like tetra- $n$ octyl ammonium provoke a collapse of the charge value $\left(1.8 \times 10^{-5} \mathrm{C}\right)$. It is quite important to underline that a direct exfoliation is not obtained with tetra- $n$-octylammonium salts without a pre-formatting with cations of smaller radii (in particular, $\mathrm{TMA}^{+}$and $\mathrm{TEA}^{+}$ammonium salts). The nature of the anion was checked to present a minor influence.

\subsection{Nature of carbon-graphite layer interfaces}

As mentioned above, charge currents of modified GC surfaces by means of deposited graphite exfoliation using a given cation led very reproducible electricity amounts (the total cathodic charge within a defined potential gap presents an average error no larger than $10 \%$ ). These values are surprisingly small. The I/V responses appear to be quite similar to those of synthetically produced polyaromatic macromolecules by oxidative condensation of hexaphenylbenzene by means of organic chemistry under suitable conditions possibly leading to graphene nano-ribbons [10].

Deposition of graphene layers with the assumption that the external one in contact with solution is lonely reactive (Scheme 1, C) implying a quasi absence of diffusion of ions TAA ${ }^{+}$ within the short times used in voltammetric sweeps) could be proposed as a plausible model. Therefore, the reduction peaks found with each $\mathrm{TAA}^{+}$salt could be regarded as the formation of graphene poly-anions stabilized by a progressive coverage of surface as potential decreases. At each cathodic peak (or plateau) would correspond a coverage level. The statistic position of $\mathrm{TAA}^{+}$ions could be seen as a soft-grafting (or marking) of some carbon atoms of graphene. Assimilating reduction peaks with successive reduction levels could permit to estimate corresponding coverage by $\mathrm{TAA}^{+}$ions. For example, with tetraethylammonium tetrafluororate, the charge found was $4.8 \times 10^{-4} \mathrm{C}$ at a surface of $7 \mathrm{~mm}^{2}$. The three steps are 
supposed to be mono-electronic transitions. A value of $2.2 \times 10^{-8}$ ion $/ \mathrm{cm}^{2} \mathrm{seems}$ high but should take into account the great surface roughness and that of the relative migration rate of those ions through the layers. Additionally, the weak electro-negativity of $\mathrm{TAA}^{+}$with the possibility to give multi-layers could be taken into account. With $\mathrm{TOABF}_{4}$, values based on mono-electronic transitions $\left(2.5 \times 10^{-9}\right.$ ion $\left./ \mathrm{cm}^{2}\right)$ fit better with the proposal described above.

\subsection{Functionalization of the interface GC-graphene}

We aim to bring briefly additional supports to the proposed model by achieving different modifications of the external layer active towards $\mathrm{TAA}^{+}$cations (at $\mathrm{E}<-1.8 \mathrm{~V}$, cathodic charge) and towards free radicals generated outside the charge zone $(\mathrm{E}>-1.8 \mathrm{~V})$.

First of all, the grafting of 2-methylanthraquinone radical (from $\mathrm{Br}_{-} \mathrm{CH}_{2}-\mathrm{AQ}$ ) was carried out both on bare GC and modified GC by graphitization. After two scans between $0 \mathrm{~V}$ and -1.5 $\mathrm{V}$ (in $\mathrm{DMF}+\mathrm{TMABF}_{4}$, scan rate: $50 \mathrm{mV} \mathrm{s}^{-1}$ ), the immobilization of AQ could be obtained: at bare GC Figure $2 \mathrm{~A}$ ), the half-peak width for the first step (radical anion of grafted AQ) is large $(210 \mathrm{mV})$, total coverage: $5 \pm 3 \times 10^{-9} \mathrm{~mol} \mathrm{~cm}^{-2}$, peak potential: $-0.88 \mathrm{~V}$. Contrariwise, the same experiments at modified GC showed important discrepancies: first, an extremely sharp cathodic peak (half-peak width: $90 \mathrm{mV}$, first scan in $\mathrm{TBABF}_{4}$ ), apparent $\mathrm{AQ}$ coverage: $12 \pm 3 \times 10^{-9} \mathrm{~mol} \mathrm{~cm}^{-2}$, peak potential: $0.83 \mathrm{~V}$ (Figure 2, B). Definitively, it does exist a fundamental difference between the two kinds of surfaces possibly brought by the specificity graphene layer (two layers of grafting giving higher levels of immobilization). One may note (Figure 2, C) an evidence for the layer to be doped concomitantly by the presence of AQ layer and the charge of graphene.

Ferrocene (by means of Fc- $\left(\mathrm{C}_{6} \mathrm{H}_{12}\right)-\mathrm{I}$ ) could be attached as well (curves D1 at graphene and D2 at GC) in both cases by using the cathodic charge of substrate $(\mathrm{E}=-2.0 \mathrm{~V})$. Superficial concentrations are $\Gamma_{\mathrm{Fc}}$ equal to $10^{-8}$ and $5 \times 10^{-9} \mathrm{~mol} \mathrm{~cm}^{-2}$ respectively (Scheme 1,B). The ratio of coverages $2 / 1$ should be noticed and $\Gamma_{\mathrm{Fc}}$ values within the same range than those given above for AQ.

\section{Conclusion.}


The method of direct exfoliation of graphite, described for the first time in this preliminary work, offers the possibility to create easily GC-graphene interfaces seen as new materials. These interfaces are specifically reactive, within the cathodic range, towards cations and organic electrophilic species. Moreover, the evidence for a doping at $\mathrm{E}<-1.8 \mathrm{~V}$, suggests large possibilities for easy chemical reactions based on redox catalysis owing to deposited graphene. Produced materials are stable, of rather good conductivity and offer unusual surface modifications that quite certainly deserve further studies and clarifications.

Acknowledgements: The author wishes to warmly thank Pr. V. Jouikov (University of Rennes, France) for his helpful support in the course of the present work.

\section{Figure caption}

\section{Figure 1}

(A) Process of exfoliation of GC-graphite surface by $\mathrm{TMABF}_{4}$. (B and C) Examples of electrochemical charges of formatted GC-graphite electrodes shown in (A) in the presence of different tetra-alkylammonium salts. Solvent: DMF. Scan rate: $50 \mathrm{mV} \mathrm{s}^{-1}$. Apparent surface areas of electrodes: $7 \mathrm{~mm}^{2}$ in $\mathrm{A}$ and $\mathrm{B}$, and $0.8 \mathrm{~mm}^{2}$ in $\mathrm{C}$

\section{Figure 2}

Electrochemical modifications of GC-graphene electrodes. Apparent surface area: $7 \mathrm{~mm}^{2}$. Scan rate: $50 \mathrm{mV} \mathrm{s}^{-1}$. A, B, and C: grafting after electrolysis obtained after 2 scans (between $0 \mathrm{~V}$ and $-1.6 \mathrm{~V})$ in a solution DMF-TEABF 4 containing $\mathrm{BrCH}_{2} \mathrm{AQ}\left(4 \times 10^{-4} \mathrm{~mol} \mathrm{~L}^{-1}\right)$. Cyclings in $\mathrm{TBABF}_{4} / \mathrm{DMF}$. A) at smooth GC. B) at GC-graphene. C) Still at GC-graphene with 1 scan until -2.4V. D1/D2): Cyclings after reductions of $\mathrm{Fc}_{-} \mathrm{C}_{6}-\mathrm{I}$ at $-2 \mathrm{~V}$ at $\mathrm{GC}$-graphene and smooth GC respectively. The inset: Nyquist plots for electroreduction of tetracyanobenzene $\left(3 \times 10^{-3}\right.$ mol L- ${ }^{1}$ ) at GC electrodes with deposited graphite layers: voltammograms of TCB at these electrodes. a and c: smooth carbon, b: GC-graphene. $\mathrm{CH}_{3} \mathrm{CN} / 0.1 \mathrm{M} \mathrm{Bu}_{4} \mathrm{NPF}_{6}, \mathrm{E}=-0.7 \mathrm{~V}, \Delta \mathrm{E}$ $=10 \mathrm{mV}$, Frequency range from $184.6 \mathrm{kHz}$ to $0.2 \mathrm{~Hz} . \mathrm{R}_{\mathrm{CT}}(\boldsymbol{b})=11.2 \mathrm{kOhm}$. 


\section{References}

[1] H. J. Schäfer, Comprehensive Organic Synthesis, Vol. 3 (Eds, B.M. Trost, I. Fleming), Pergamon Press, New York, 1991.

[2] G. M. Jenkins, K. Kawamura, Nature, 231 (1971) 175.

[3] P. J. F. Harris, Philosophical Mag., 84 (2004) 3159.

[4] C. Dano, J. Simonet, J. Electroanal. Chem., 564 (2004) 115.

[5] J.O. Besenhard, Carbon, 14 (1976) 111.

[6] J. Simonet, H. Lund, J. Electroanal. Chem., 77 (1977) 719.

[7] V. Jouikov, J. Simonet, Electrochem. Comm., Mini-review, 45 (2014) 32.

[8] A. Ambrosi, C. C; Chua, A. Bonanni, M. Pumera, Chem. Rev., 114 (2014) 7150 and quoted references.

[9] V. Jouikov, J. Simonet, Electrochem. Comm., (2014) in press and cited references.

[10] E. Ussano, G. Valenti, M. Iurlo, F. Paolucci, M. Marcaccio, Communication, 10th ECHEMS 2014, Wells, UK. 


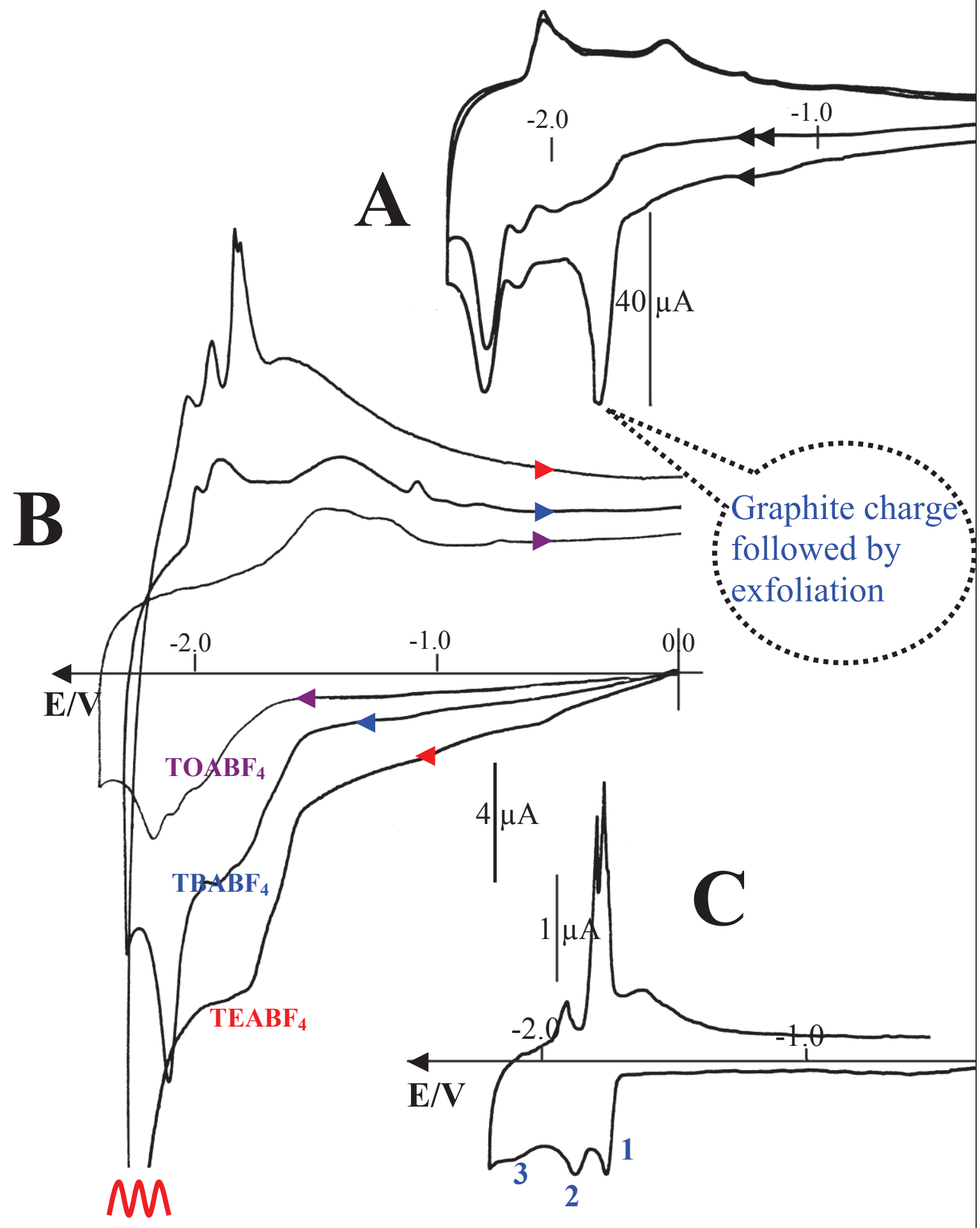

Figure 1 


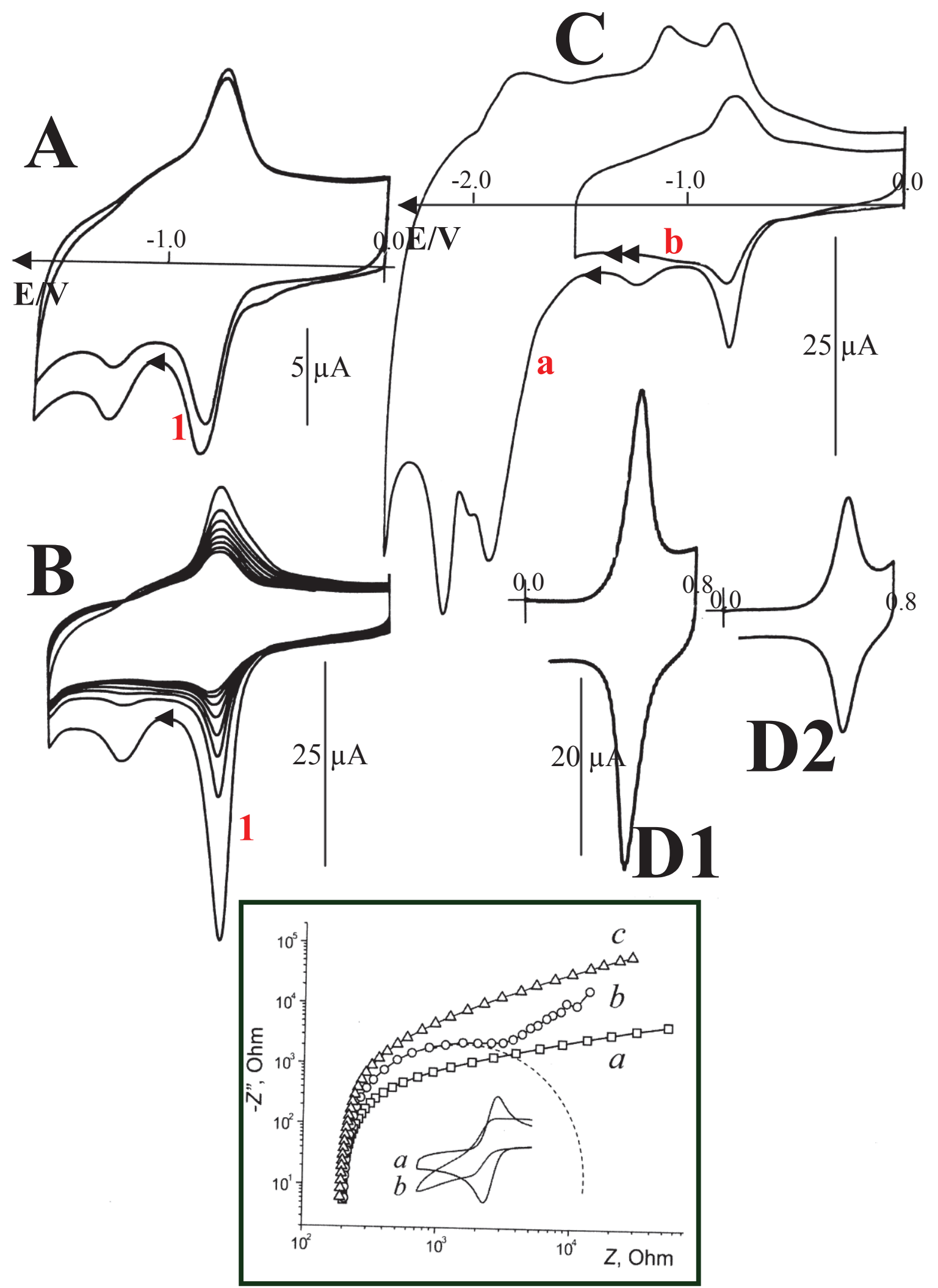

Figure 2 

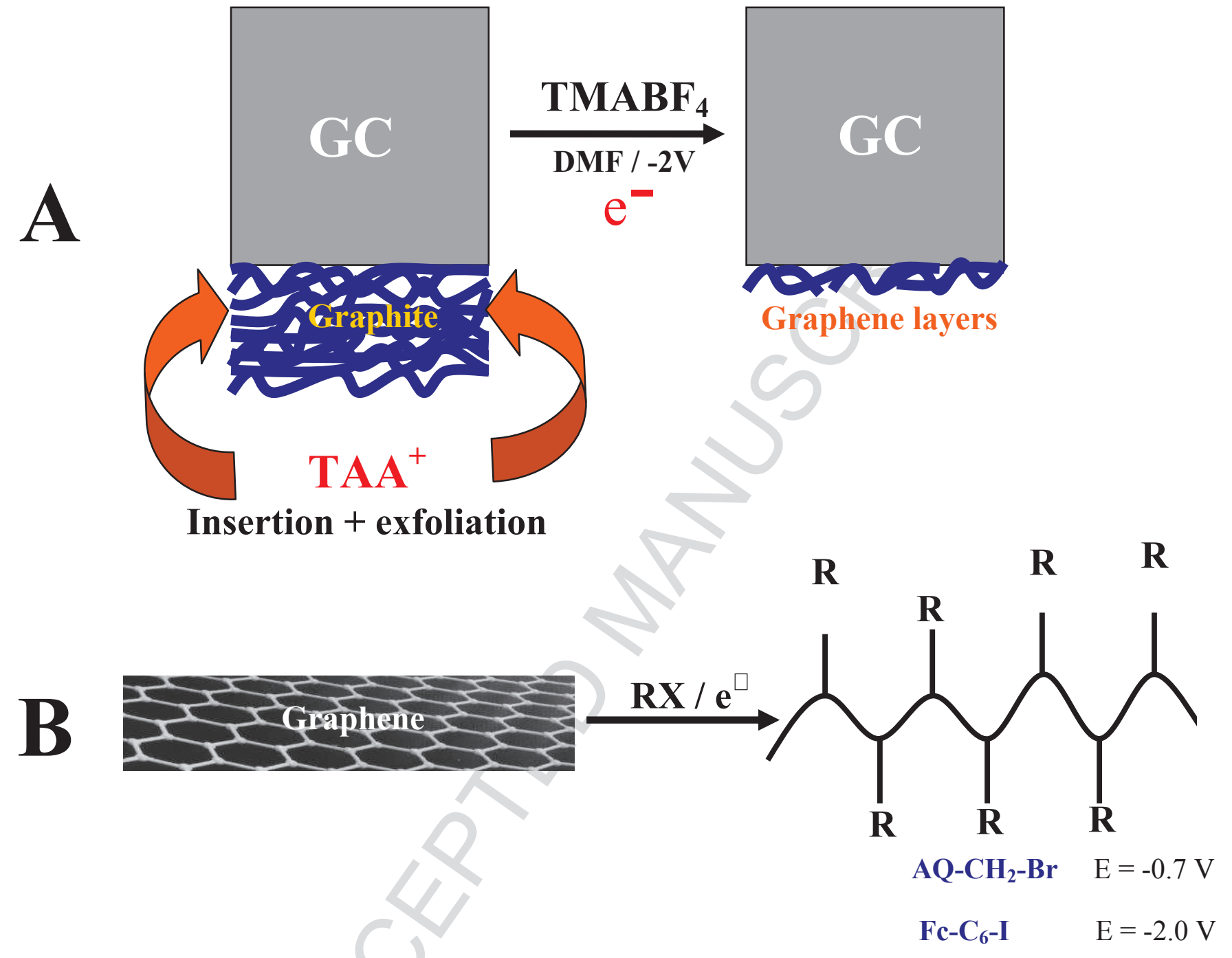

C

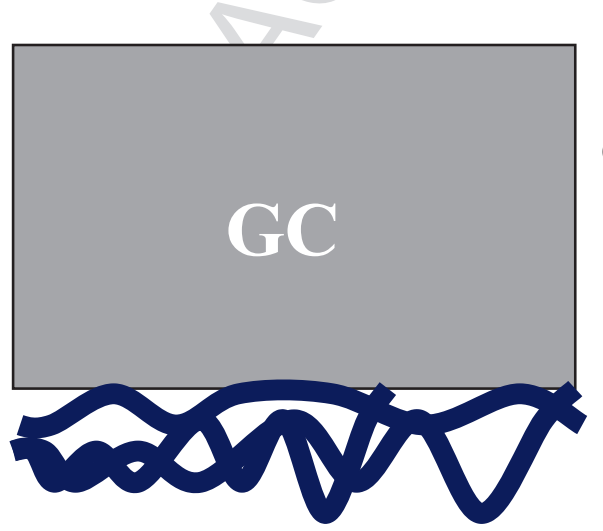

Cathodic charge external graphene

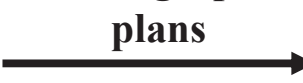

TAA $^{+}\{\bigcirc\}$, DMF, $\mathrm{E}<-\mathbf{- 1 . 8 V}$

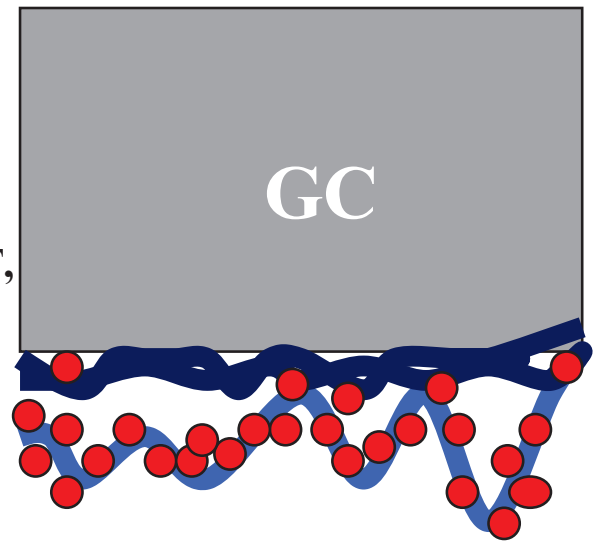




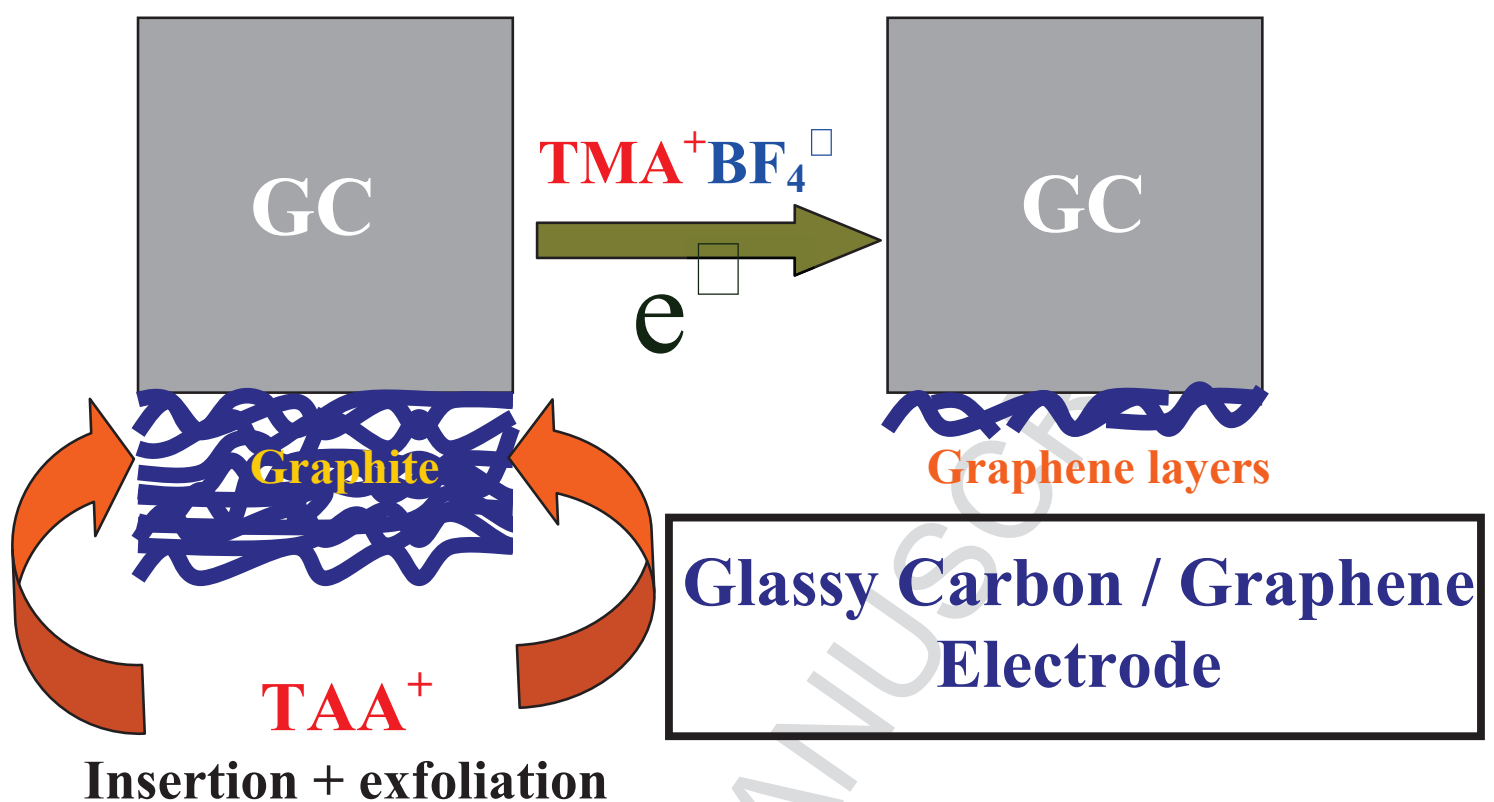

Graphical Abstract 


\section{Highlights}

Exfoliation of graphite was achieved at solid surfaces

$>$ Very thin and highly stable deposits of graphene layers were obtained at smooth glassy carbon

$>$ The specificity of several tetraalkylammonium salts (TAA+X-) was shown in the charge / cathodic reduction of those layers

$>$ Preliminary modifications by ferrocene and anthraquinone moieties were achieved at those graphene layers. 